\title{
EVOLUCIÓN DE UNA IDEA: DE LA CIBERNÉTICAA LA CIBERCULTURA LA FILOSOFÍA GRIEGA Y LA CIBERNÉTICA ${ }^{1}$
}

\author{
Omar Esteban Barbosa Martínez ${ }^{2}$ \\ Universidad Santo Tomás
}

\section{Resumen}

\begin{abstract}
El presente texto indaga sobre el origen del concepto de cibernética y su relación con la cibercultura. En 1948 Norbert Wiener propone el concepto de cibernética para reunir toda una gama de teorías que se venían desarrollando antes y durante la segunda guerra mundial. Aunque el concepto se popularizó desde entonces, pocas veces nos preguntamos por su verdadero origen. Así es como iniciamos un recorrido por algunos textos de filósofos griegos como Anaximandro, Platón y Aristóteles, en donde el término cibernética es usado con diversos sentidos, los cuales pueden servir de base para una interpretación de lo que hoy día se denomina la cibercultura. Este escrito hace parte de una investigación más amplia en la que se pretende encontrar el sentido de aquello que llamamos cibernética y sus repercusiones en la cultura o cibercultura.
\end{abstract}

\section{Palabras clave}

Cibernética, cibercultura, filosofía griega, ciberespacio

\footnotetext{
1 Este escrito es parte del capítulo Evolución de una idea: de la cibernética a la cibercultura, dentro del proyecto de investigación Cibercultura y cultura en América Latina, en la línea de investigación Filosofía de la educación en Colombia y América Latina, vinculada al Centro de Investigaciones de la Facultad de Filosofía y Letras en el programa de Maestría en Filosofía Latinoamericana de la Universidad Santo Tomás, y presentado en el I Encuentro de investigadores en filosofía y cultura, el 23 de junio de 2004.

2 Profesor de la Maestría en Filosofía Latinoamericana, Universidad Santo Tomás, Bogotá. Correo: omar_barbosa@yahoo.com.
} 


\begin{abstract}
The present text investigates on the origin of the cybernetics concept and its relation with the cibercultura. In 1948 Norbert Wiener it proposes the cybernetics concept to reunite all a range of theories that came developing before and during World War II. Although the concept became popular since then, not very often we were asked for its true origin. Thus it is as we initiated a route by some texts of Greek philosophers like Anaximandro, Plato and Aristotle, in where the term cybernetics is used with diverse senses, which can serve as base for an interpretation of which nowadays the ciberculture is denominated. This writing is part of one more an ampler investigation in the one than it is tried to find the sense what we called cybernetics and its repercussions in the culture or ciberculture.
\end{abstract}

\title{
Index terms
}

Cybernetics, ciberculture, Greek philosophy, cyberspace.

\section{Introducción}

Una y otra vez sucede que el prefijo ciber o cyber se relaciona con la tecnología de la información y con internet. Bajo este contexto se encuentran términos tales como ciberdemocracia, ciberterrorismo, cibersexo, cibercomercio -y muchos otros más que no resultan difíciles de generar de esta misma forma. Cada una de ellas está justificada por el grado intencional de la formalidad del lenguaje de acuerdo a su dependencia contextual, pero pocas veces nos hemos preguntado lo que realmente significa, qué nos quieren decir con eso, cuál ha sido su origen, hacia dónde se orientan.

Si la filosofía consiste en dar sentido al mundo y a todo aquello que nos rodea, una de las primeras cosas que tenemos que hacer en nuestra “ciberépoca” es encontrar el sentido de aquello que llamamos cibernética y sus repercusiones en la cultura, para abreviar, la cibercultura. Nuestra preocupación se centra en la pregunta: ¿cuál ha sido la recepción que ha tenido la cibercultura en la cultura latinoamericana, específicamente en la educación? A grandes trazos, este es el proble- ma que pretendemos estudiar en el proyecto de investigación Impacto de la cibercultura en la educación latinoamericana.

Así, en el primer capítulo de nuestro proyecto haremos una descripción del estado actual de la cibercultura, en especial de la evolución que ha tendido dicha concepción desde sus orígenes en Grecia hasta la transformación en nuestros días. En el segundo capítulo profundizaremos en las transformaciones que se han presentado en el paso de la cultura a lo que se ha llamado la cibercultura, y así mismo tocaremos algunas teorías que consideran lo que hoy llamamos cibercultura como un fenómeno que se ha venido presentado de forma implícita a lo largo de la historia. En el tercer capítulo hablaremos de las transformaciones que se presentan desde la cibercultura a la cultura, es decir, cómo aquellos fenómenos que se pueden considerar netamente ciberculturales adquieren el status de cultural, para sostener la hipótesis de que el fenómeno cibercultura poco a poco ha ido ampliando su espectro transformacional. En el cuarto capítulo analizaremos el fenómeno de la cibercultura en América Latina, en especial su recepción e 
impacto, es decir, veremos cómo este fenómeno mundial adquiere sus propias características y su propia manera de ser en la cultura latinoamericana, tipificada en el campo educativo. Y en el último capítulo hablaremos de algunos principios y fundamentos que podrían sustentar una teoría cibercultural y cibereducativa para América Latina.

Para este encuentro ofreceré un avance de la primera parte de la investigación, correspondiente a los orígenes y evolución de las nociones de cibernética, ciberespacio y cibercultura, puntos de partida de lo que hoy llamamos cibercultura.

\section{Evolución de una idea: de la cibernética a la cibercultura}

Hay dos ideas que han revolucionado el pensamiento en los últimos cincuenta años: la idea de cibernética y la idea de ciberespacio. Para entender dicha revolución es necesario que veamos la evolución y la relación que entre las dos se han presentado.

En 1948 Norbert Wiener, en su libro Cybernetics, or control and communication in the animal and the machine $e^{3}$, propone el concepto de cibernética para reunir toda una gama de teorías que se venían desarrollando antes y durante la segunda guerra mundial: "la cibernética es la ciencia de la dirección y comunicación en los organismos vivos y en las máquinas”; pero en 1951 la amplía a la sociedad en The human use of human being: cybernetics and society ${ }^{4}$.

Más tarde William Gibson, en 1984, en su novela Neuromante (Nuuromance), primera de una trilogía compuesta, además, por Conde Cero (Count Zero, 1986) y Mona Lisa acelerada (Mona Lisa Overdrived, 1988), utiliza el neologismo ciberespacio para designar "una alucinación consensual experimentada diariamente por billones de legítimos operadores en todas las naciones... Una representación gráfica de la información abstraída de los bancos de todos los ordenadores (computadoras) del sistema humano. Una complejidad inimaginable"5. Aunque se ha dicho que el término apareció por primera vez en Neuromante, éste fue usado antes por Gibson en un cuento que forma parte del volumen Quemando cromo (Burning Chrome, 1981).

Pero volvamos a Wiener, pues quizás una de las mejores maneras para ilustrar una nueva idea, y ver su fuerza y el impacto, sea encontrar su origen y, desde allí, ver la evolución que ha tenido en la historia del pensamiento de la humanidad. Cuando en 1948 el matemático Norbert Wiener emplea el término cibernética para designar su nueva propuesta sobre el control y la comunicación en las máquinas y los organismos vivos, nos dice: "Hemos decidido llamar a toda la materia referente al control y teoría de la comunicación, tanto en la máquina como en el animal, con el nombre de cibernética”. "Has-

3 WIENER, Norbert. Cybernetics, or control and communication in the animal and the machine. París: Hermann Editions; Cambridge: MIT Press; New York: Wiley \& Sons, 1948.

4 WIENER, Norbert. The human use of human being: cybernetics and society. London: Free Association Books, 1954.

5 GIBSON, William. Neuromante. Traducción de José Arconada y Javier Ferreira. Minotauro, 1996, p. 35. "Cyberspace. A consensual hallucination experienced daily by billions of legitimate operators, in every nation, by children being taught mathematical concepts... A graphic representation of data abstracted from the banks of every computer in the human system. Un-thinkable complexity”. Neuromancer. New York: Berkley Publishing Group, 1989, p. 128. 
ta hace muy poco tiempo no existía una voz que comprendiera ese conjunto de ideas; para poder expresarlo todo mediante una palabra, me vi obligado a inventarla" 6 . Sin embargo, nos advierte que dicho término fue tomado de los griegos y especialmente de Platón: “Ciertamente que ya Platón empleó la palabra en el sentido de forma de pilotar una nave... La palabra, en fin, procede etimológicamente del griego Kybernetes, piloto, timonel, de ahí su sentido actual"”.

Así es como hemos iniciado la tarea de averiguar en qué textos de Platón se usó dicho término y el sentido que en ellos se encuentra. En nuestras pesquisas hemos hallado que no solamente Platón lo utilizó, pues también lo encontramos en algunos presocráticos, en Aristóteles y en Jenofonte. ¿En qué sentido lo utilizaron?

\subsection{La noción de “cibernética” en la filosofía griega}

A continuación, transcribiremos algunas citas de estos pensadores griegos con sus respectivas referencias. Para su comprensión, hemos colocado la cita en griego y su versión en la traducción española. Al final haremos una interpretación sobre el sentido del término en cada una de sus formas.

Según la página electrónica Perseus, en la catalogación y frecuencia de uso que se hace del término en los textos griegos, hasta el momento digitalizados, la estadística es la siguiente: Platón, 27 veces; Aristóteles, 5;
Epíteto, 2; Polibio, 1; y Jenofonte, 1; para un total de 36 veces. Además, hemos encontrado que G. S. Kirk, J. E. Raven y M. Schofield, en Los filósofos presocráticos: historia crítica con selección de textos, nos presentan algunos pasajes en los que presocráticos como Heráclito, Parménides y Diógenes de Apolonia hacen uso de dicho concepto. Veamos algunos ejemplos.

1. Aristóteles, en la Física, recordando los planteamientos de Anaximandro sobre el principio rector del cosmos, nos dice que: “...lo infinito no tiene principio..., sino que parece ser ello el principio de los demás seres y que todo lo abarca y todo lo gobierna, como afirman cuantos postulan otras causas fuera de lo infinito, tales como el espíritu o la amistad; el infinito, además, es un ser divino, pues es inmortal e indestructible, como afirman Anaximandro y la mayoría de los físicos teóricos”(Aristóteles, Fís. 4, 203 b 7) ${ }^{8}$. En este texto griego encontramos ya el término $k \cup \beta \varepsilon v \alpha \hat{v} v$, utilizado por Anaximandro y otros físicos teóricos, entre los que se encuentran Heráclito, Parménides y Diógenes de Apolonia. Sus afirmaciones constatan que la sustancia primaria "todo lo abarca y todo lo gobierna" es una materia primaria infinita pero no causada separada del movimiento. Tratar de comprender qué tipo de control ejercía sobre todos los seres el Infinito de Anaximandro es el interrogante que surge aquí.

6 WIENER, Norbert. Cibernética y sociedad. Traducción de José Novo Cerro. Colección Índice, Ciencia. Buenos Aires: Editorial Sudamericana, 1969, p. 15.

7 Ibídem.

8 Citado en: KIRK, G. S., RAVEN, J. E. y SCHOFIELD, M. Los filósofos presocráticos: historia crítica con

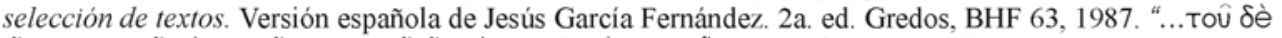

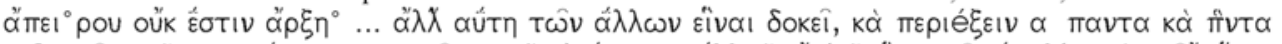

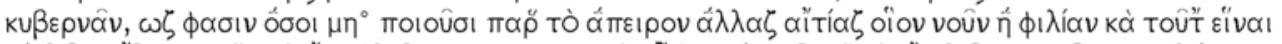

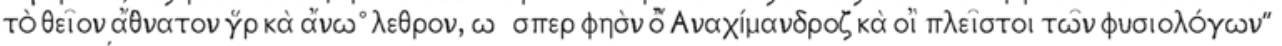
(ARISTÓTELES, Fis. 4, 203 b 7). 
2. En Platón, autor griego de quien se han conservado más referencias, cibernética (kubernetes) es el arte de pilotear la nave. Entre sus varios testimonios, leemos en Ión:

\section{Sócrates:}

¿Por qué posee esta técnica o por alguna otra causa?

Ion:

Porque posee esta técnica.

Sócrates:

$\mathrm{Y}$ ¿no es verdad que a cada una de estas técnicas le ha sido concedida por la divinidad la facultad de entender en un dominio concreto, porque aquellas cosas que conocemos por la técnica del timonel, no las conocemos por la medicina?

Ion:

Seguro que no ${ }^{9}$.

3. En Aristóteles destaquemos estas dos referencias en la Ética a Nicómaco:

En 111b, 1-5 leemos:

Sobre los conocimientos rigurosos y suficientes no hay deliberación, por ejem- plo, sobre las letras (porque no vacilamos sobre el modo de escribirlas); pero sobre todo lo que se hace por mediación nuestra aunque no siempre de la misma manera, deliberamos; por ejemplo, sobre las cuestiones médicas o de negocios, y mas sobre la navegación que sobre la gimnasia, en la medida en que la primera está mas lejos de haber alcanzado la exactitud, y lo mismo sobre todo lo demás, pero más sobre las artes que sobre las ciencias, porque vacilamos más sobre las primeras $^{10}$.

Y en 1104a, 5, afirma:

Y si la exposición general ha de ser de esta naturaleza, con mayor razón carecerá de precisión la de lo particular, que no cae bajo el dominio de ningún arte ni precepto, sino que los mismos que actúan tienen que considerar siempre lo que es oportuno, como ocurre también en el arte de la medicina y en el del piloto. Pero aun siendo de esta naturaleza nuestro presente estudio, debemos intentar aportar nuestra contribución ${ }^{11}$.

Un análisis inicial de estos planteamientos nos muestra que para Anaximandro y los

9 Ion, 537c

¿ôkpatêo

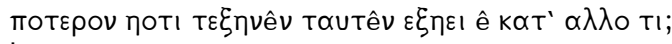

lôv

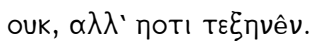

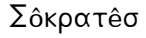

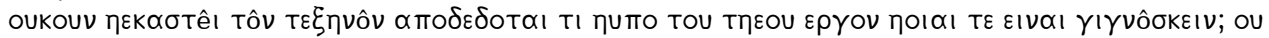

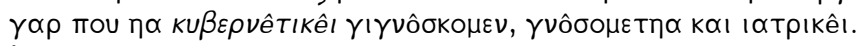

lôv

ou dêta.

10 ARISTÓTELES. Etica a Nicómaco, 1112b, 1-5. Edición bilingüe y traducción por Mará Araujo y Julián

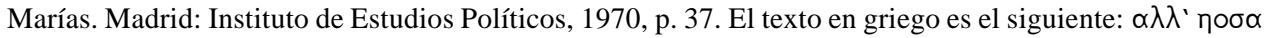

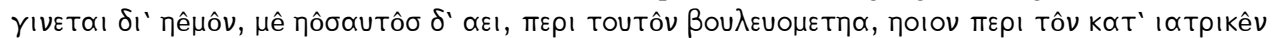

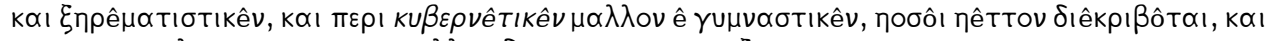

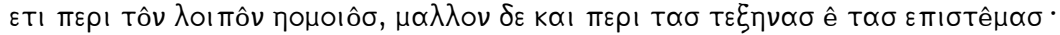

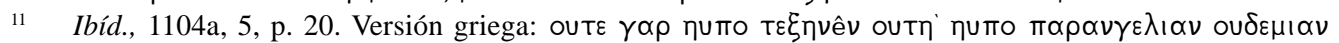

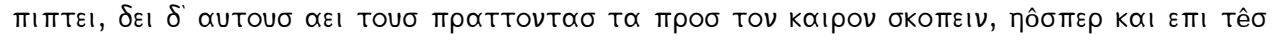

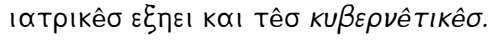


presocráticos la cibernética se relaciona con el gobierno que ejerce la divinidad sobre la totalidad: "todo lo abarca y todo lo gobierna”. Platón, por su parte, restringe el término a ejemplo para ilustrar las afirmaciones que se hacen sobre el arte (techné). Y para Aristóteles, la noción sirve de término analogado para hablar de la virtud, específicamente sobre la deliberación, en su sentido práctico de "acción prudente".

Pero la cibernética obviamente no se circunscribe al helénico «arte de gobernar un timón», pues es un concepto mucho más amplio, ya que involucra la nave, su capitán, el piloto y timonel. Ciertamente, siguiendo a Guilbaud, el piloto es ejemplo de pensamiento cibernético, puesto que situado entre el capitán que fija el objetivo y el timonel que lleva el buque, elige el programa de acción y da las órdenes al timonel. El piloto, quien controla, gobierna u ordena el rumbo del barco, tiene, previamente, que estar informado no sólo de a dónde ha de dirigirse (orden del capitán), sino del estado de la mar, velocidad y dirección de los vientos, etc. Recibe toda esta información y toma una decisión: el rumbo. Así es como la cibernética, en su acepción actual, se extiende al estudio del funcionamiento de toda clase de sistemas.

Es por ello por lo que el propio Wiener, en Cibernética y sociedad, su segunda obra, dice:

Cuando controlo las acciones de otra persona le comunico un mensaje y aunque este sea de naturaleza imperativa, la técnica de la comunicación no difiere de la técnica de la transmisión de un hecho. Por demás, si deseo que mi control sea eficaz, debo informarme de todos los men- sajes procedentes de la persona, capaces de advertirme que la orden ha sido comprendida y ejecutada ${ }^{12}$.

\subsection{La noción de cibernética en el pensamiento moderno}

Desde los tiempos de su origen -en la Grecia clásica de hace 2.500 años- hasta el siglo XIX, no existieron referencias populares conocidas que relacionaran el vocablo "cibernética” con el concepto divulgado por Norbert Wiener.

Fue en 1834 que André-Marie Ampère (1775-1836), en su vasto Ensayo sobre la filosofía de las ciencias, obra inacabada y que decía ser «una exposición natural de los conocimientos humanos», buscando un término científico lo más preciso posible para connotar el sentido intrínseco del gobierno, afrancesó la antigua palabra griega y la lanzó al mundo científico como la cybernétique. Ampère sitúa la cibernética como la parte de la política que trata de los medios de gobernar, o estudio de las formas de gobernar. El gran diccionario de la lengua francesa de Littré, así como el antiguo Larousse la registraron definitivamente.

Pero como ya hemos relatado, fue en 1948 y sin conexión, al parecer, con la iniciativa de Ampère, que el matemático americano Norbert Wiener publicó la obra que puso definitivamente en circulación y de moda la vieja palabra kybernetiké, que tomó también del griego: Cybernetics, or control and communication in the animal and the machine. Así, la palabra cibernética fue reinventada por Norbert Weiner en 1948, a partir del vocablo griego kubernetes, que significa piloto o timonel.

12 WIENER, Norbert. Cibernética y sociedad. Traducción de José Novo Cerro. Colección Índice, Ciencia. Buenos Aires: Editorial Sudamericana, 1969, p. 23. 
Después de 1950, con el desarrollo fulminante de las aplicaciones de la electrónica, la voz corrió por todos los ambientes e hizo continuo uso de ella la prensa, vulgarizándola.

Una definición más filosófica, sugerida por Louis Conffignal en 1958, considera la cibernética como "el arte del aseguramiento de la eficiencia de la acción”"13.

Para el filósofo Warren McCulloch, la cibernética era una epistemología experimental interesada por la comunicación en el interior de un observador y entre el observador y su entorno.

William Ross Ashby ${ }^{14}$ (1903-1972), autor británico de los libros clásicos Design for a brain (1952) e Introduction to cybernetics (1956), y Stafford Beer, ayudaron a enriquecer el estudio y la aplicación de los conceptos cibernéticos en las más variadas disciplinas, especialmente en la administración de empresas, en cuyo campo se ha destacado el último de los nombrados. Este último definió la cibernética como la ciencia de la organización efectiva.

El antropólogo Gregory Bateson observó que, mientras las ciencias antes trataban con la materia y la energía, la nueva ciencia de la cibernética se enfoca a las formas y los patrones.

Para Margaret Mead, la cibernética es una forma de ver las cosas y un lenguaje para expresar lo que uno ve.

El académico ruso A. N. Kolmogórov, en su prefacio a la traducción al ruso del libro de W. Ross Ashby Introducción a la cibernéti$c a$, define el contenido conceptual de esta disciplina científica en los términos siguientes: "La cibernética se ocupa de estudiar los sistemas de cualquier naturaleza capaces de percibir, conservar y transformar información y utilizarla para la dirección y la regulación”"15.

Después de la propuesta de Norbert Wiener surge una línea de investigación dedicada a reflexionar lo que sería la "filosofía de la cibernética”. En este campo encontramos autores como Helmar G. Frank, con su obra Cibernética y filosofía: materiales y esbozos para una filosofía de la cibernética (1974); Jean Ladriere, con Filosofía de la cibernética (1958); y Frederick Crosson, Filosofía y cibernética (1967).

Hoy la emplean, además de los matemáticos y físicos, los economistas, sociólogos, contadores, químicos, estadígrafos y muchos otros.

Se puede explicar que la cibernética abarca, al menos por ahora, tres grandes esferas: los mecanismos guiados (palabras en el sentido de «regulación»), personal que maneja máquinas (palabras con el sentido de "piloto») y sociedades autorreguladas (palabras como «gobierno»).

\section{De la novela a la cultura}

Como habíamos dicho anteriormente, es William Gibson quien acuña el neologismo "ciberespacio" para designar al conjunto de servicios de información y espacios virtuales de comunicación accesibles a través de las redes digitales de transmisión de datos (internet). Las novelas de Gibson describen

\footnotetext{
13 COUfFignAL, Louis. La cibernética. Traducción de Francisco Asensio y Antonio Arbones. Barcelona: Redondo, 1970, p. 44.

14 ROSS ASHBY, William. Introducción a la cibernética. Buenos Aires: Ediciones Nueva Visión, 1960.

15 Ibíd., p. 10.
} 
un mundo muy similar al actual, sólo que en un tecnofuturo. Aparece el poder y la confrontación de las grandes corporaciones, el mercado de la información como materia prima de la nueva realidad y, como detonador de la acción, los traficantes o ladrones de esa información.

El ciberespacio es como un antilugar o un otrolugar donde se escenifica la acción de personajes enchufados a través de sus consolas. Cuando se comenzaron a escribir estos libros, ni siquiera había computadoras personales en los escritorios de personas comunes y silvestres.

Pero después de la novela de William Gibson, surge una línea dedicada a tratar de entender el ciberespacio, en tres grandes momentos surgimiento, crítica y difusión-, de donde surge lo que hoy día tenemos sobre la ideas del ciber. Así hemos pasado a hablar de cibercultura, cibergobierno, etc., pero, ¿cómo entenderlos?

Para Pierre Levy, el ciberespacio, es un “espacio metafórico, espacio de comunicación, abierto por la interconexión mundial de los ordenadores" ${ }^{\text {"16 }}$, mientras que la cibercultura “es el conjunto de técnicas, de maneras de hacer, de maneras de ser, de valores, de representaciones que están relacionadas con la extensión del ciberespacio...”17.

Cibercultura se refiere a los modos de vida, las formas de construcción del self y del otro, así como las formas en las que fluyen transversalmente las dimensiones política y económica en la espiral de dominación/re- sistencia dentro de este nuevo y escurridizo escenario llamado cyberspace o ciberespacio. En su sentido más abarcador, remite a toda forma de comunicación mediada por redes de computadoras $(C M C)$, ya sea en tiempo diferido -como cuando utilizamos el correo electrónico- o en tiempo sincrónico, como cuando sostenemos una conversación en un chat room de Internet Relay Chat, o interactuamos con otros en ambientes virtuales como los $\mathrm{MOO}^{18}$.

Así, la cibercultura puede ser entendida, de forma pragmática y provisional, como un objeto de estudio, la ubicamos en la trama de relaciones múltiples y complejas de las poblaciones humanas con todo su entorno social y noológico en devenir, es decir, sus ecologías simbólicas confrontadas en diferentes momentos y procesos (adaptación, rechazo, autoproducción, adopción, interacción como auxiliar o como plataforma generativa) con las tecnologías digitales (dispositivos, procesos y representaciones que implican información codificada electrónica-mente en dígitos) y con la comunicación mediada por computadoras, que a su vez abarca también una variada y creciente gama de procesos, posibilidades, plataformas y representaciones de lo social ${ }^{19}$.

Por otra parte, la cibercultura puede ser entendida como un estratégico valor de desarrollo social que se concreta en el rediseño de tres culturas/cultivos de nuestras habilidades prácticas y representaciones sobre la información, el conocimiento y la comunicación ${ }^{20}$.

16 LEVY, Pierre. “Ciberespai i cibercultura.” Artículo presentado en la Universitat Oberta de Catalunya. Barcelona, 1999.

17 Ibíd.

18 FIGUEROA SARRIERA, Heidi J. y CARROLL, Joseph. Cibercultura. http://home.coqui.net/hfiguero/ ciber.htm.

19 GONZÁLEZ, Jorge A. Cultura(s) y Ciber cultur@s: incursiones no lineales entre complejidad y comunicación. México: Universidad Iberoamericana, 2003. Hay vínculo a la introducción en: http:// www.unam.mx/ceiich/complex/labcc/dicc.html.

20 Ibídem. 